\title{
PEMBUATAN APLIKASI ECOMMERCE USAHA MIKRO KECIL DAN MENENGAH (UMKM) WAROENG BU DHEVI
}

\author{
Dedi Trisnawarman ${ }^{1}$, Muhammad Choirul Imam², Jaceline Chan ${ }^{3}$, Afina Putri Dayanti ${ }^{4}$, \\ dan Amalia Nurain ${ }^{5}$
}

\author{
1, 2, 3, 4, 5 Program Studi Sistem Informasi, Universitas Tarumanagara Jakarta \\ Surel:dedit@fti.untar.ac.id
}

\begin{abstract}
Usaha Mikro Kecil dan menengah (UMKM) are one of the micro businesses that empower home industries. Indonesian UMKMs have a contribution of $15.8 \%$ to the global production supply chain at the ASEAN level. The development of MSMEs from year to year is influenced by the use of information technology and information systems. E-commerce is one of the technologies that support the development of SMEs and trade today. The number of Micro, Small and Medium Enterprises (UMKMs) joining e-commerce is increasing. Until August 2021, more than 14 million UMKMs or 22 percent of the total UMKMs have joined the e-commerce electronic trading application. UMKM Waroeng Bu Dhev was established on 27 February 2020 and is located at Bumi Menteng Asri Housing Complex, Jl. Therapy IIa BA 8, RT01/17 Bogor. Engaged in the business of making and selling various foods, such as Lapis Maksuba, Lapis Engkak, Dimsum, Choipan, Pastries, Kastengles, Nastar and so on. Currently, Waroeng Bu Dhev's marketing is still using the traditional method, namely word of mouth. There has been no marketing effort through promotional activities and sales using other media. The purpose of this Community Service activity is to help develop Waroeng Bu Dhev SMEs through e-commerce promotion media, especially in terms of product promotion and sales. The ecomerce design method uses a prototyping software application, namely by involving the user iteratively in each design phase. The e-commerce application built consists of 9 menus, namely: Shop, Update \& Promo, Store Location, FAQ, Search Products, Your Account, Your Cart, dvpradono@gmail.com, and WHATSAPP.
\end{abstract}

Keywords: e-commerce, UMKMs, promotion, food

\begin{abstract}
ABSTRAK
Usaha Mikro Kecil dan menengah (UMKM) merupakan salah satu usaha mikro yang memberdayakan industri rumahan. UMKM Indonesia memiliki kontribusi sebesar $15.8 \%$ terhadap rantai pasok produksi global di tingkat ASEAN. Perkembangan UMKM dari tahun ke tahun dipengaruhi dengan pemanfaatan teknologi informasi dan sistem informasi. E-commerce merupakan salah satu teknologi yang mendukung perkembangan UMKM dan perdagangan saat ini. jumlah Usaha Mikro, Kecil, dan Menengah (UMKM) yang bergabung dengan e-commerce semakin meningkat. Sampai Agustus tahun 2021 sudah lebih dari 14 juta UMKM atau 22 persen dari total UMKM, yang sudah bergabung dengan aplikasi perdagangan elektronik e-commerce. UMKM Waroeng Bu Dhev berdiri sejak tanggal 27 februari 2020 dan berlokasi di Perumahan Bumi Menteng Asri J1. Terapi IIa BA 8, RT01/17 Bogor. Bergerak dalam bidang usaha pembuatan dan penjualan aneka makanan, seperti Lapis Maksuba, Lapis Engkak, Dimsum, Choipan, Kue kering, Kastengles, Nastar dan sebagainya. Pemasaran yang dilakuan Waroeng Bu Dhev saat ini masih melalui cara tradisional, yaitu dari mulut ke mulut. Belum ada upaya pemasaran melalui kegiatan promosi dan penjualan menggunakan media lainnya. Tujuan kegiatan Pengabdian kepada Masyarakat ini adalah membantu pengembangan UMKM Waroeng Bu Dhev melalui media promosi ecommerce, khususnya dalam hal promosi dan penjualan produk. Metode perancangan ecoomerce menggunakan aplikasi perangkat lunak prototyping, yaitu dengan melibatkan user secara iteratif pada setiap fase perancangan. Aplikasi ecommerce yang dibangun terdiri dari 9 menu, yaitu: Shop, Update \& Promo, Lokasi Toko, FAQ, Search Products, Your Account, Your Cart, dvpradono@gmail.com, dan WHATSAPP.
\end{abstract}

Kata Kunci: e-commerce, UMKM, promosi, makanan 


\section{PENDAHULUAN}

Organisasi membutuhkan teknologi informasi, terutama pada saat ini agar bisnis organisasi menjadi lebih efektif dan efisien. Ecommerce merupakan salah satu bagian teknologi informasi yang dapat mendukung hal tersebut (Ardiansyah, 2021).

Mumtahana, dkk. (2017) menyatakan bahwa industri rumahan dapat diberdayakan melalui usaha mikro yaitu UMKM, masih menurut Mumtahana, dkk bahwa di ASEAN produksi suply chain secara global, dimana Indonesia dengan UMKMnya menyumbang 15,8\%. Hal ini juga menunjukkan dengan seiring berjalannya waktu, penerapan teknologi informasi dan sistem informasi meningkatkan petumbuhan UMKM.

Teknologi web mulai merambah banyak aspek kehidupan kita sehari-hari dan pentingnya sebagai media transaksi bisnis akan tumbuh secara signifikan selama beberapa tahun ke depan. Tirtana, dkk., 2020 mendefinisikan E-commerce aktifitas atau transaksi penjualan dan pembelian menggunakan media elektronik jaringan internet seperti aplikasi website. Aplikasi ecommerce dapat mengurangi biaya operasional dan memperbesar dan meningkakan pangsa pasar. Informasi juga dengan cepat langsung didapatkan, komunikasi dengan antara penjual dan pembeli juga bisa langsung dilakukan secara online dan real tome.

UMKM memberikan kontribusi terhadap pertumbuhan ekonomi Indonesia. Terdapat 55,2 juta UMKM di Indonesia pada tahun 2012, meningkat menjadi 62,9 juta pada tahun 2017, suatu penambahan angka yang sangat berarti, yaitu 7,7 juta UMKM (Putra, 2016).

Usaha Mikro Kecil dan menengah (UMKM) Waroeng Bu Dhev berdiri sejak tanggal 27 februari 2020 dan berlokasi di Perumahan Bumi Menteng Asri Jl. Terapi IIa BA 8, RT01/17 Bogor. Bergerak dalam bidang usaha pembuatan dan penjualan aneka makanan, seperti Lapis Maksuba, Lapis Engkak, Dimsum, Choipan, Kue kering, Kastengles, Nastar dan sebagainya. Pemasaran yang dilakuan Waroeng $\mathrm{Bu}$ Dhev saat ini masih melalui cara tradisional, yaitu dari mulut ke mulut. Belum ada upaya pemasaran melalui kegiatan promosi dan media lainnya.

\section{METODE PELAKSANAAN PKM}

Perancangan aplikasi ecommerce menggunakan metode prototyping (Denis dkk., 2015). Dalam metode prototyping terdapat beberapa tahapan dimana user terlibat secara interaktif dan dilakukan berulang.

Dalam situasi PPKM yang masih berlangsung saat ini, proses perancangan dilakukan dengan menggunakan media daring (online) yaitu whats up, email dan zoom meeting. Prototipe aplikasi yang telah dibuat dapat langsung dijalankan oleh pengguna, sehingga pengguna langsung dapat memberikan masukan untuk perbaikan berikutnya.

\section{HASIL DAN PEMBAHASAN}

PKM yang telah dijalankan menghasilkan aplikasi ecommerce, aplikasi tersebut dapat diakses pengguna melalui alamat web https://waroengbudhev.com/. Selain itu juga dibuat buku manual pengguna yang dapat digunakan untuk memudahkan penggunaan website.

Aplikasi ecommerce yang dihasilkan terdiri dari menu-menu seperti yang dapat dilihat pada pada Gambar 1, hierarki menu. 


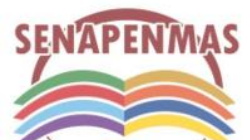

2021
Seminar Nasional Hasil Penelitian dan Pengabdian Kepada Masyarakat 2021

Pengembangan Ekonomi Bangsa Melalui Inovasi Digital Hasil Penelitian dan Pengabdian Kepada Masyarakat Jakarta, 21 Oktober 2021

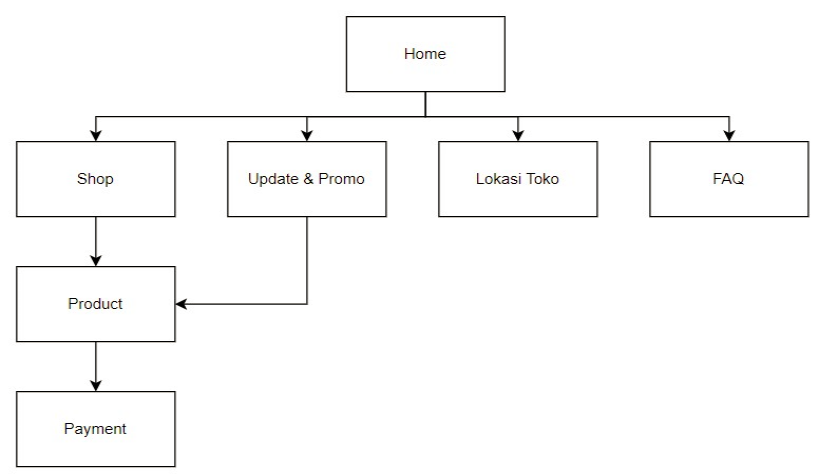

Gambar 1. Hirarki Menu

Sedangkan dihalaman beranda pada Gambar 2, terdapat menu sebagai berikut:

- Shop

- Update \& Promo

- Lokasi Toko

- FAQ

- Search Products

- Your Account

- Your Cart

- dvpradono@gmail.com

- WHATSAPP

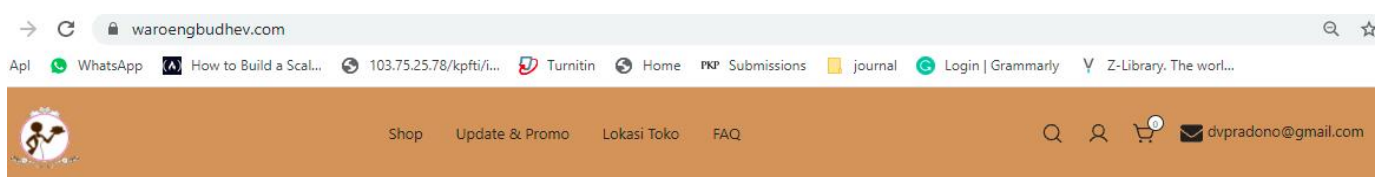

\section{Welcome to Waroeng Bu Dhev!}

\section{SHop Now:}

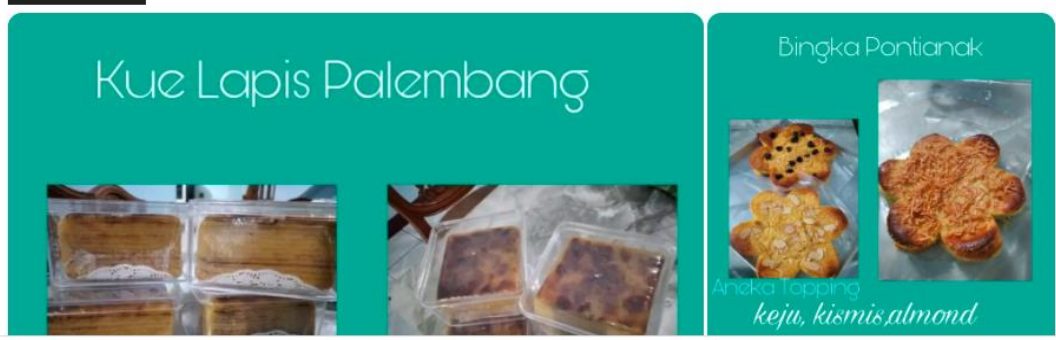

Gambar 2. Halaman beranda aplikasi ecommerce Waroeng Bu Dhev

Pada menu Shop, jika diklik akan muncul gambar-gambar produk beserta harga, seperti yang terlihat pada Gambar 3. 


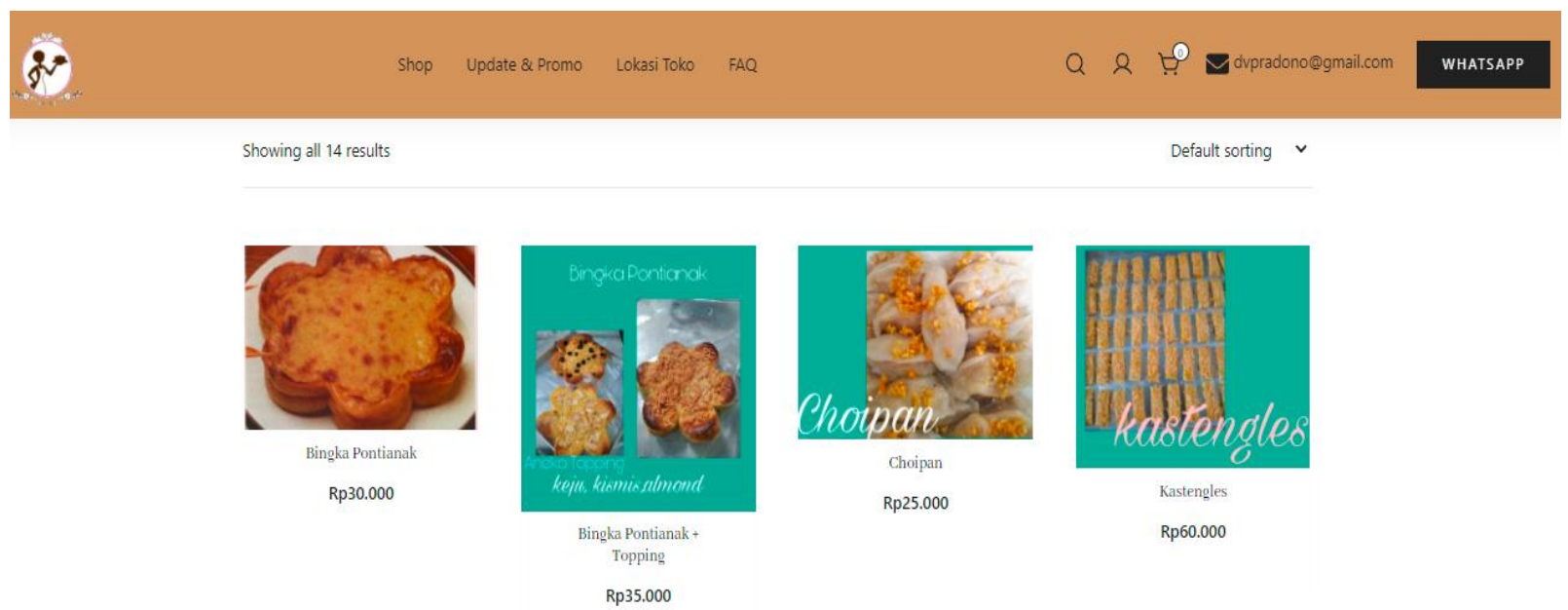

Gambar 3. Menu Shop

Selanjutnya menu Update dan Promo, adalah menu untuk mengupdate pesanan dan promosi produk yang ditawarkan, untuk menu Lokasi Toko, ketika diklik akan menampilkan peta alamat lokasi toko fisik (Gambar 4).

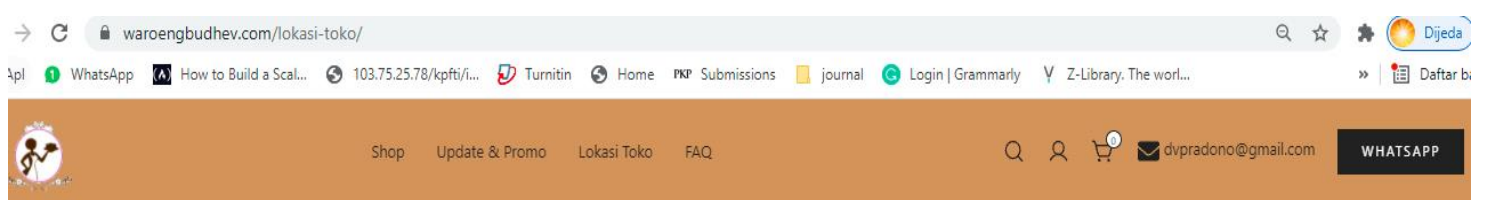

\section{Lokasi Toko}

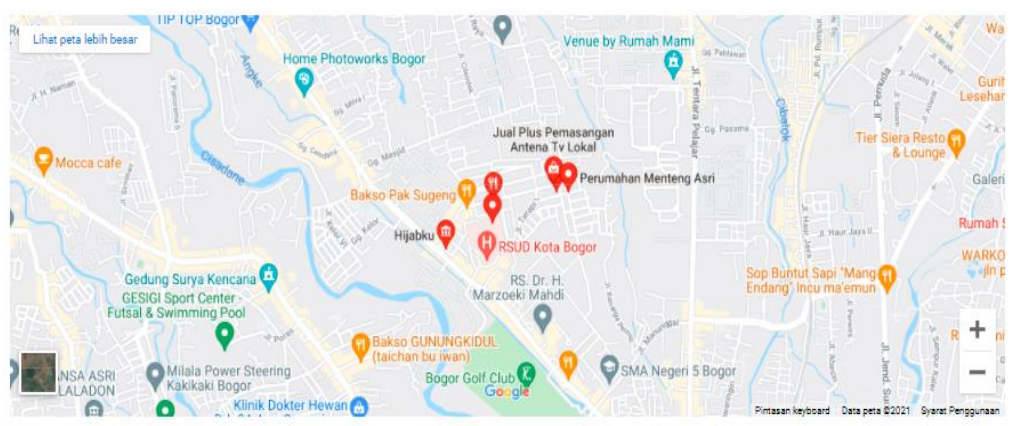

Gambar 4. Peta alamat lokasi toko

Menu selanjutnya FAQ atau Frequently Asked Questions akan menampilkan informasi yang kemungkinan paling sering ditanyakan oleh pelanggan, yaitu cara pemesanan, cara registrasi dan metode pembayaran, Gambar 5. 


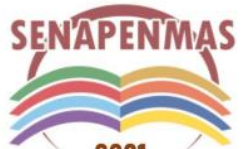

2021
Seminar Nasional Hasil Penelitian dan Pengabdian Kepada Masyarakat 2021

Pengembangan Ekonomi Bangsa Melalui Inovasi Digital Hasil Penelitian dan Pengabdian Kepada Masyarakat Jakarta, 21 Oktober 2021

Apl OShatsApp (N) How to Builda Scal...

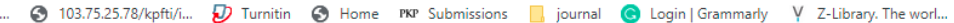

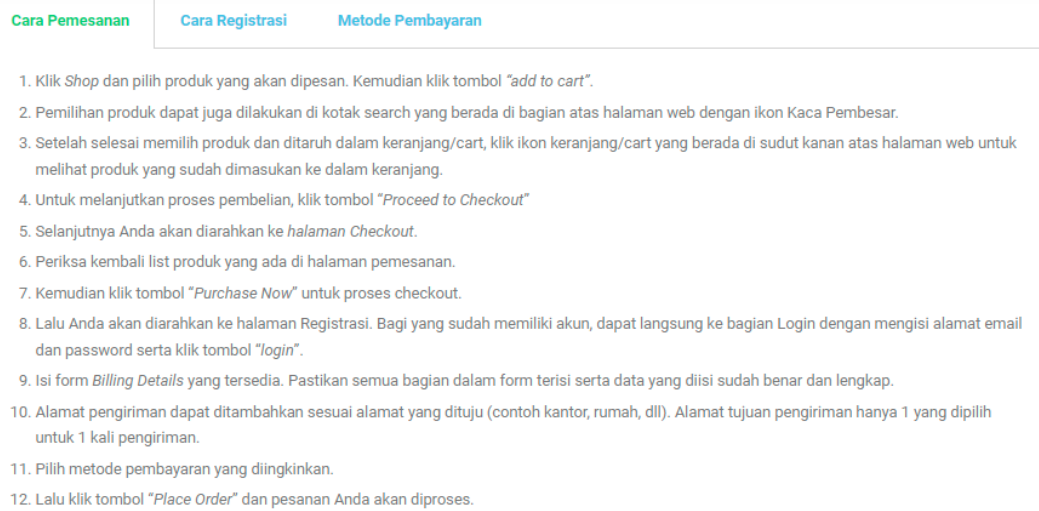

Gambar 5. Frequently Asked Questions

Selanjutnya, menu search digunakan untuk membatu pecarian secara cepat, terutama jika produk yang dijual sudah semakin banyak (Gambar 6).

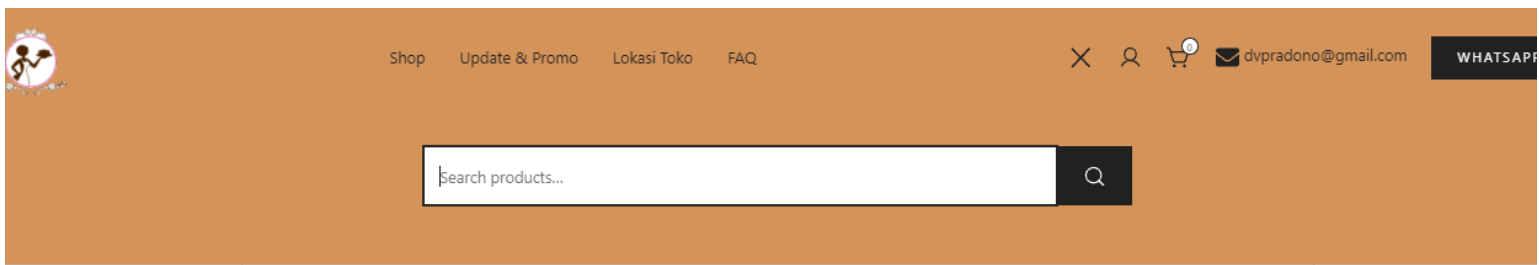

Gambar 6. Menu search

Menu My Account digunakan untuk melakukan pendaftaran bagi pelanggan yang akan melakukan transaksi pemesanan, seperti pada Gambar 7.

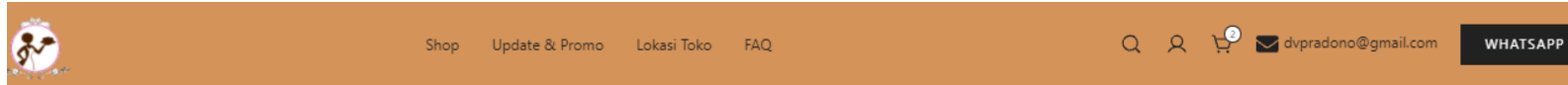

\section{Cart}

\begin{tabular}{|c|c|c|c|c|}
\hline & PROOUCT & PRICE & QUANTITY & SUBtotal \\
\hline$\times$ & Bingka Pontianak & Rp 30.000 & \begin{tabular}{|ll}
$-1+$ \\
\end{tabular} & Rp30.000 \\
\hline$\times$ & Bingka Pontianak + Topping & Rp 35.000 & $-1+$ & Rp 35.000 \\
\hline Coupon code & APPLY COUPON & & & UPDATE CART \\
\hline
\end{tabular}

Gambar 7. Tampilan menu your account 


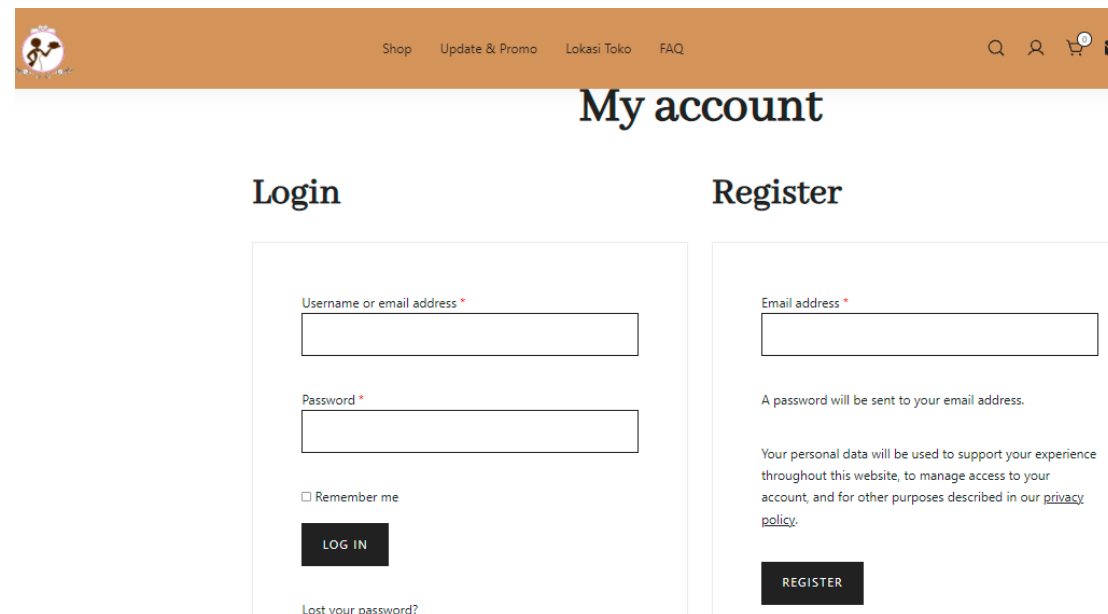

Gambar 8. Tampilan menu Cart

\section{KESIMPULAN DAN SARAN}

Pelaksanaan kegiatan PkM yang telah dilakukan berhasil membangun sebuah aplikasi ecommerce. Penerapan aplikasi ecommerce tersebut dapat digunakan oleh mitra sebagai jalan keluar permasalahan pada saat pandemi saat ini yaitu untuk kegiatan promosi dan transaksi penjualan. Selain itu untuk melengkapi aplikasi dibuat juga buku manual aplikasi. Buku manual ini ditujuakn untuk membantu dalam menjalankan aplikasi oleh pengguna dan administrator web aplikasi.

\section{Ucapan Terima Kasih (Acknowledgement)}

Ucapan terimakasih ditujukan kepada LPPM Universitas Tarumanagara yang telah mendukung dan memfasilitasi kegiatan Pengabdian kepada Masyarakat ini.

\section{REFERENSI}

Ardiansyah, T. (2021). Model Platform E-Commerce Dalam Mendukung Kesuksesan Bisnis Usaha Mikro Kecil \& Menengah (UMKM). Jurnal Pemasaran Kompetitif, 4(2), 197-211.

Dennis, A., Wixom, B. H., \& Roth, R. M. (2015). Systems analysis and design. John wiley \& sons.

Mumtahana, H. A., Nita, S., \& Tito, A. W. (2017). Pemanfaatan Web E-Commerce untuk meningkatkan strategi pemasaran. Khazanah Informatika: Jurnal Ilmu Komputer dan Informatika, 3(1), 6-15.

Putra, A. H. (2016). Peran UMKM dalam pembangunan dan kesejahteraan masyarakat kabupaten Blora. Jurnal Analisa Sosiologi, 5(2).

Tirtana, A., Zulkarnain, A., Kristanto, B.K., Suhendra, S. and Hamzah, M.A., (2020). Rancang Bangun Aplikasi E-Commerce Untuk Meningkatkan Pendapatan UMKM. Jurnal Ilmiah Teknologi Informasi Asia, 14(2), pp.101-108. 